\title{
NEW SOURCES OF GROWTH: THE ROLE OF FRUGAL INNOVATION AND TRANSFORMATIONAL LEADERSHIP
}

\author{
Solikin M. Juhro* and A . Farid Aulia** \\ " Bank Indonesia Institute, Jakarta, Indonesia. Email: solikin@bi.go.id \\ ** Bank Indonesia Institute, Jakarta, Indonesia. Email: arasta@bi.go.id
}

\begin{abstract}
This paper's main thesis is that frugal innovation and transformational leadership offer additional sources of growth. Our main contribution is the proposal of what we refer to as the breakthrough possibility frontier (BPF) model, which integrates two aspects of leadership: innovation quality (frugal innovation) and leadership competency (transformational leadership). We test the BPF model on two groups of respondents, one group consisting of university students who had never been formal leaders and the other formal leaders who had office experience. The BPF analysis suggests that transformational leadership is a game changer, required for breakthroughs. Transformational leadership is key to encouraging innovation quality and leadership competency and, we argue, to facilitating new sources of growth. Our results imply the development of an integrated institutional framework for innovation. We believe that innovative leadership development programs that can be easily implemented and replicated in other regions are needed to develop transformational leadership competencies.
\end{abstract}

Keywords: New sources of growth; Innovation; Frugal innovation; Transformational leadership; Breakthrough possibility frontier.

JEL Classifications: O31; O33; O43.

Article history:

Received : July 15, 2019

Revised : October 10, 2019

Accepted : October 11, 2019

Available online : October 15, 2019

https://doi.org/10.21098/bemp.v22i3.1195 


\section{BACKGROUND}

After the 2008-2009 global financial crisis, global economic growth stagnated, entering a new norm, below its previous long-term trend. According to the World Bank, from 2014 to 2018, global economic growth averaged 3\%, down from an average rate of $4 \%$ from 2003 to 2007. Indonesia's economy fared better than other emerging market economies, averaging 5\% growth from 2014 to 2018 (IMF, 2018). ${ }^{1}$ However, Indonesia's relatively stagnant growth stoked government concerns over the issue of the middle-income trap and the country's capability of realizing its long-term goal of becoming a high-income country by 2030 .

Indonesia's target is an income per capita of US $\$ 13,000$ by 2030, which can only be achieved through annual economic growth of $10 \%$. If economic growth averages $5 \%$, however, Indonesia will end up with a per-capita gross domestic product of only US $\$ 7,247$. This $10 \%$ economic growth target is deemed unrealistic, since very few countries are able to sustain double-digit growth. If Indonesia fails to accomplish this target, it can potentially fall into the middle-income trap and thus fail to transition toward becoming a developed country. ${ }^{2}$

Governments need to pay more attention to the current situation, characterized by a continually shifting and developing technology (otherwise known as technological progress or technological revolution ${ }^{3}$ ). The state is required to adapt to various economic problems through appropriate leadership. Economic processes and progress will ensure that those with the requisite managerial capabilities become more prosperous. Nevertheless, some of the world's more disadvantaged citizens in terms of access, knowledge, and capabilities will be left behind and exposed to a labor market dominated by high value-adding industries that rely on skills and technology. National underdevelopment forces people to find innovative solutions to their problems. Innovation exists to encourage economic growth (Schumpeter, 1949) and to remove the shackles of poverty and ignorance that widen economic and social gaps (Food and Agriculture Organization, 2018). Innovation by means of technological advancement is considered part of the economic process and is endogenous to the economy itself (Carlaw \& Lipsey, 2006).

Supported by innovation and technological capabilities, Indonesia is expected to transition towards becoming a developed country, with all societal elements enjoying the fruits of development and welfare (Bappenas, 2011). In the future, Indonesia's economic growth is expected to become more sustainable and inclusive, with high value added. Consequently, the course of future development must encourage effective innovation that empowers and brings prosperity to all of society. Indonesia has vast potential to become a developed country because of several factors, such as solid economic fundamentals, abundant natural endowments, and the demographic bonus of a huge population of productive

\footnotetext{
1 From 2009 to 2013, Indonesia's economic growth was one of the highest in South Asia, averaging 6\%, and it also had inflation under control, at around 5\% (World Economic Outlook, 2018).

2 According to the World Bank, out of 101 countries, only 13 escaped the middle-income trap and have transitioned into high-income, developed countries, with a middle-income trap period averaging 42 years.

3 Including the digital revolution, artificial intelligence, robotics, and other cases of the Industrial Revolution 4.0.
} 
age. However, achieving the status of a developed country is not easy. Indonesia is currently facing many binding constraints to economic growth, especially inadequate infrastructure to encourage investment and business expansion, as well as a lack of quality education and vocational training to raise productivity.

Rapid change requires innovation. A highly innovative country will enjoy economic power as a corollary of its competitive advantage in the international market (Fu et al., 2010). To catch up with the growth rates in developed countries, developing countries must respond rapidly to changes and their implications in other sectors through responsive policies. Low-income countries can achieve poverty reduction, economic growth, and the equitable distribution of goods and services if manufacturers have access to low-scale, labor-intensive technologies and produce low-cost products accessible to low-income consumers (Kaplinsky, 2011).

Such dynamics have triggered the emergence of frugal innovation in developing countries. Frugal innovation is a design process that prioritizes the public's needs and circumstances in developing countries to innovate products and services that are adaptable, affordable, and accessible (Basu et al., 2013). Frugal innovation usually emerges in populous countries with a high level of income inequality, such as India and China. Innovation serves the needs of the working class, taking advantage of any available resources and less expensive designs and product development to ensure more affordable prices. In other words, it is a sound and affordable solution that can satisfy the needs of consumers with limited resources (Zeschky, Widenmayer, \& Gassmann, 2011).

Frugal innovation is a realistic choice for Indonesia, since it is oriented toward providing economically affordable technology. Technology users with limited financial power usually require simpler technology that supports their micro, small, and medium-sized economic activities. Frugal innovation contains not only a social dimension, but also a business dimension. This approach optimistically appreciates the capabilities of the working class struggling at the very bottom of the pyramid. Frugal innovation encourages individuals to sharpen their creativity and innovative entrepreneurship (Prahalad, 2005).

Indonesia needs to achieve solid and balanced economic growth. Frugal innovation, with its game-changing characteristics, can help realize this need through various competitive business activities at the global level. To eradicate poverty and reduce social gaps, Indonesia requires more inclusive and diverse growth processes. Efforts to encourage frugal innovation will succeed if Indonesia can first realize the prerequisites for changing the mindsets of major technology developers and policymakers.

This challenging situation requires strong leadership (Raghuramapatruni \& Kosuri, 2017) enabled by new competencies that were not required in the previous era (Lawrence, 2013). Organizations endowed with effective leadership will have three times as many opportunities to become top organizations (Axon, Friedman, \& Jordan, 2015). It cannot be overstated that leadership is a critical element of every organization (Charan, 2009), including when leveraging a country's economic growth. Therefore, leaders in the public or private sectors must be more committed to inclusive development and balanced growth to enhance the standard of living for all (World Economic Forum, 2017). 
This study considers transformational leadership to be another important aspect to be analyzed in innovation and growth. Transformational leadership is a type of participatory leadership that aims to produce changes in the morale, internal motivation, and performance of followers to effectively support organizational goals (Burns, 1978; Bass, 1990; Juhro \& Aulia, 2018). Transformational leadership competencies relate directly to the emergence of innovation at an organization. The key determinants of innovation include vision, openness, backing for innovation, autonomy, encouragement, appreciation of followers, and challenges (Elkins \& Keller, 2003). Moreover, innovation relates closely to the quality of decision making and agility (Kock \& Gemünden, 2016), which are also two transformational leadership competencies (Juhro \& Aulia, 2018). Transformational leadership positively affects an organization's creativity and innovation (Gumusluoglu \& Ilsev, 2007). Accordingly, a transformational leader is required to realize an atmosphere conducive to innovation.

The goal of our paper is to explore the issues relating to frugal innovation and transformational leadership as an effective approach to discovering new sources of economic growth. Tactically, the question this study seeks to answer is, How do innovation quality and leadership competency play a strategic role in facilitating new sources of growth? In answering this question, we propose and offer a new approach, namely, the breakthrough possibility frontier (BPF) model, presenting the role of transformational leadership as a game changer with its ability to create breakthroughs in facilitating new sources of growth. The role of transformational leadership enters the growth story through the encouragement of innovation quality and leadership competency.

Several studies have explored the role of frugal innovation in economic growth. Our position in this literature is unique because, while we do focus on frugal innovation, we nonetheless cover new aspects of growth, namely, leadership competencies (of transformational leadership) and the required institutional arrangement. Our contribution to the literature on growth is through the innovation and leadership perspectives. We draw policy implications as a result of this approach.

This study consists of five sections. Section II elaborates on selected literature on the growth paradigm, frugal innovation, and transformational leadership as a game changer. Section III describes the methodology and data, and Section IV presents the analysis based on the BPF model. Section V concludes the paper with implications.

\section{LITERATURE REVIEW}

\section{A. Growth Paradigm and the Role of Innovation}

Economic growth theories and paradigms evolve and develop over time. Initially, economic growth theory emphasized the utilization of manpower and physical capital as pro-growth factors. The theory was extended and refined through the inclusion of other determinants (e.g., technology and innovation, as well as the quality of human capital) that provided a more comprehensive story of the patterns of economic growth (i.e., endogenous growth theory). Later, innovation 
was included as a primary factor that was perceived as encouraging productivity growth and, subsequently, economic growth.

Numerous efforts (e.g., Koellinger, 2008; Karadal \& Saygin, 2011; Zhao \& Lei, 2013) have been made to understand the relation between technological progress and innovation at both the sector and macroeconomic levels. Innovation, we argue, is also linked to research and development (R\&D) and leadership (Chersbrough, 2003; García-Morales, et al., 2008). Technological progress has made the world more connected, without rigid borders. In 2013, the Organisation for Economic Co-operation and Development (OECD) realized the potential for developing a knowledge-based economy and became more dependent on knowledge than during the previous era. It was estimated that, from 1995 to 2007, investments in knowledge-based capital (KBC) contributed an average of $23 \%$ to manpower productivity gains (Corrado et al., 2012). KBC, together with R\&D, software, human capital, and organizational structure, plays an integral role in enhancing productivity and productive efficiency. By investing in $\mathrm{KBC}$, corporations in OECD countries have secured a comparative advantage relative to peer countries. Since then, several developing countries have prioritized KBC investment (OECD, 2013).

Countries are innovative in that they seek new and more sustainable sources of economic growth. Therefore, a model that can enhance productivity and reduce adverse impacts on natural resources is required to generate economic growth. A new, innovative, more efficient, and affordable model will facilitate productivity and economic growth.

\section{B. Frugal Innovation: What, Why, and How?}

B1. What Is Frugal Innovation?

Traditional economic growth stimuli have become obsolete and irrelevant and must be adjusted to the current era. Amid complex challenges, cooperation among different stakeholders (private-public sectors, nongovernmental organizations, etc.) and/or bilateral/multilateral cooperation (at the international level) are required to produce the best solutions to achieve broader economic opportunities such as higher levels of employment, wage increases, and welfare enhancement. Growth must be socioeconomically and environmentally sustainable (Baker, 2015). The need for innovation to enhance economic growth has become more urgent. This is because greater competition, due to greater economic integration brought about by globalization and the financialization of global economic and financial systems, requires countries to now be more efficient, competitive, and productive. As countries become increasingly driven by innovation, endogenous growth theory is becoming more prominent in explaining growth, because at the heart of this theory are investments in innovation, human resources, and science and technology. These types of investments are perceived to drive economic growth (OECD, 2004).

One component of innovation, namely, frugal innovation, significantly influences economic growth and social sustainability (Khan, 2016). Frugal innovation not only takes advantage of cheap labor, but also redesigns products and processes that reduce expenses, thus enhancing competitiveness and 
efficiency (Woodridge, 2010). A more succinct definition of frugal innovation is a design process that prioritizes the public's needs and circumstances in developing countries to innovate adaptable, affordable, and accessible products and services (Basu et al., 2013; Bound \& Thornton, 2012). In terms of limited resources, the products of frugal innovation often have inferior features, including simpler and cheaper raw materials (Zeschky et al., 2011; LIPI, 2013); however, the products are still considered adequate by their user base (LIPI, 2013). The advantages of frugal innovation include not only lower costs but also better quality than the competition (and/or alternatives). Moreover, such products can be manufactured on a large scale. Consequently, the relevance of frugal innovation lies in its social mission (in terms of greater affordability and accessibility for lower-income groups) and through continuous improvement.

Frugal innovation requires several criteria to exist: (1) a substantial and significant reduction in costs; (2) a focus on the main functions and specific innovation objectives; and (3) performance optimization through the alignment of methods toward a common purpose (Weyrauch \& Herstatt, 2017). Bhatti (2018) further elaborates the criteria for frugal innovation as follows: (1) affordability, (2) accessibility, (3) simplicity, (4) sustainability, (5) quality, and (6) purpose.

\section{B2. Why is Frugal Innovation Relevant?}

As mentioned above, frugal innovation contains an element of sustainability. According to the literature, frugal innovation and sustainable innovation have a common objective, that is, to enhance inclusive economic development. The overarching target of frugal innovation is the purchasing power of the working class, especially in developing countries. Sustainable innovation does not really focus on economic aspects; rather, it focuses on the needs of the base of the pyramid when defining new products and services. Basu et al. (2013) consider frugal innovation when trying to create a sustainable solution (Le Bas, 2016). Moreover, frugal innovation is a factor that can affect economic development (Le Bas, 2016). On the one hand, with frugal innovation, low-income earners are engaged as customers. On the other hand, for the innovator creating the product, frugal innovation can be exploited to reduce $R \& D$, manufacturing, or production costs. It is safe to assume that frugal innovation, as an economic development factor (Le Bas, 2016), represents the revitalization of a matured industry.

Frugal innovation should be considered a qualified leadership instrument to make a person a true economic game changer. Not only is frugal innovation a key driver of economic growth, but also it can help a country achieve sustainable growth. Since the role of frugal innovation is sufficiently open, at a more integrated level, there is a strong notion that, for innovation to be sustainable and become a game changer, a structured innovation approach should be applied to complement frugal innovation implementation. There are five reasons why a structured innovation approach is required in terms of innovation: it ensures that (1) innovation is efficient and effective throughout the entire process, (2) the innovation is significant (although not always urgent), (3) an innovator learns from failure to innovate and should be properly rewarded when the innovation succeeds, (4) an innovator has an opportunity to analyze both the stagnancy of 
an innovation due to bureaucracy and the possibility of making resources more efficient, and (5) structured innovation can distinguish which innovations have been performing well and which ones less so, based on a study conducted by the Product Development and Management Association.

\section{B3. How is Frugal Innovation Relevant?}

Frugal innovation has significant impacts on economic growth (Ojha \& Ayilavarapu, 2016). In India, frugal innovation in various business sectors has had a positive impact on economic growth over time. Various frugal innovations conducted in India have played a significant role in alleviating poverty, creating jobs, expanding financial access (especially to low-income earners), creating equal opportunities in various fields, and empowering society through education and skill development; in other words, frugal innovation has played a significant role in generating greater impact with less effort (George, McGahan, \& Prabhu, 2012).

\section{Transformational Leadership as a Game Changer}

Constraints, specifically on local resources, require a leader who can discern any favorable effects. Nevertheless, a resource constraint is not always negative, nor must it result in adversity (Barden \& Morgan, 2015). When exploited, a constraint can become an empowering factor that results in the discovery of new problem-solving resources that might not have been considered previously due to complacency. Therefore, appropriate skills and characteristics are required to separate and view the constraints from a different perspective.

A leader must be able to affect and motivate followers so that they work constructively toward a common vision. A leader must create an organization beyond the constraints; a leader does not avoid constraints. In fact, a leader must be able to convince followers that improvements are in progress and will be realized in time. A leader must be emotionally involved with the followers to nurture commitment to change. A change in the leader's mindset and perspective on constraints can serve as the basis for frugal innovation. Frugal innovation requires necessitates a mindset that can find opportunities in any given situation, not just those resulting from constraints, and requires the leader to focus on the values of innovation rather than be threatened by constraint.

The concept of transformational leadership is developed more intensely because of its relevance in the uncertainty the world is currently facing. Transformational leadership can potentially achieve more than other types of leadership (Juhro \& Aulia, 2018). Transformational leadership consists of nine competencies (Juhro \& Aulia, 2018): (i) the ability to achieve breakthroughs, (ii) agility, (iii) emotional intelligence, (iv) social intelligence, (v) the ability to influence others, (vi) communication skills, (vii) vision, (viii) the ability to solve problems, and (ix) the ability to make decisions. Changes implemented by good transformational leaders are not merely temporary but also sustainable. Sustainability implies endurability, but sustainability is created by paying attention to the environment, now and in the future (Hargreaves \& Fink, 2000). Sustainability is also defined 
as a system's capacity to be engaged with a level of complexity of sustainable development consistent with human values (Fullan, 2004).

Consequently, personal and organizational decisions will have a positive impact on a society's socioeconomic status. The seven principles of sustainable leadership are (1) depth and leadership that matters, (2) endurance and leadership that lasts, (3) breadth, including interdependence and collaboration, (4) justice and the active spread of knowledge and resources to the environment, (5) diversity and encouragement of a cohesive difference, (6) resourcefulness, and (7) the conservation, appreciation, and development of past leadership (Hargreaves \& Fink, 2016). These principles are relatively synonymous with transformational leadership competencies.

Social issues, such as poverty, health, education, and gender equality, continue to plague countries around the world. Overall, however, the global poverty rate continues to decrease (World Bank, 2018) beyond expectations. East Asian and Pacific countries, especially China and Indonesia, as well as South Asian countries, such as India, have contributed the most to the decline in global poverty. Nevertheless, lower poverty rates in some regions accompanied by higher poverty rates in others have exacerbated the poverty gap. Broad income disparity greatly impacts gaps in other aspects, such as health, education, and gender equality. Limited access to education is considered a primary cause of high poverty (Jerim, 2013). This will become an incessant problem if not properly and effectively addressed. The social gap is a global problem that demands a global solution, as included in the Sustainable Development Goals proposed by the United Nations.

To achieve these global objectives, a transformational leader is expected to be an economic game changer, namely, a leader capable of making breakthroughs that greatly impact society, both financially and socially, and a leader who has nationalistic insight and sustainability. Transformational leadership fosters organizational creativity and innovation (Gumusluoglu \& Ilsev, 2007). Leaderfollower emotional relationships affect the level of creativity and innovation (Hunt et al., 2004). Furthermore, Juhro and Aulia (2018) show that creativity is supported by a relaxed feeling, which can be generated through good rapport with a psychologically safe leader.

\section{METHODOLOGY AND DATA}

\section{A. Measures of Innovation Quality and Leadership Competency}

Our study aims to explore frugal innovation and transformational leadership as variables in facilitating new sources of economic growth amid the current rapid pace of global technological advancement. This research is performed by constructing reality and social phenomena and interpreting these phenomena (Bryman \& Bell, 2011; Creswell, 2014). The conclusion is drawn inductively by connecting the data and theory to understanding the roles of frugal innovation and transformational leadership in the search for new sources of economic growth. Therefore, a qualitative approach is appropriate to achieve the objectives of the study, as argued, for instance, by Creswell (2014).

This study measures leadership competency by employing the nine transformational leadership competencies elaborated by Juhro and Aulia (2018). 
As explained earlier, these competencies are relatively synonymous with the sustainable leadership characteristic described by Hargreaves and Fink (2016). Innovation quality is measured based on the design process of frugal innovation. We define the scope of the design process as covering five stages of innovation strategy: (i) problem identification, (ii) value creation, (iii) significance, (iv) feasibility, and (v) impact. These aspects are aimed at targeting the frugal innovation criteria of Bhatti (2011), namely, affordability, accessibility, simplicity, sustainability, quality, and purpose.

In this regard, the first stage identifies the issues relating to the criteria of frugal innovation, namely, accessibility and purpose. The second stage is to create value in relation to the frugal innovation criteria of quality and purpose. Innovation that can create value is quality innovation based on a clear purpose. The third stage involves the significance of the innovation created to solve the problem. Quality innovation produces a specific solution to a specific problem. The frugal innovation criteria in this category are sustainability, quality, and purpose. Next is implementation potential (feasibility), which is based on affordability, accessibility, and simplicity. A feasible innovation is affordable in terms of both the manufacturing process and to the end user, accessible, and simple. The fifth stage applies impact analysis to frugal innovation criteria, namely accessibility, sustainability, quality, and purpose. Impactful innovation is easily accessible and contains elements of social inclusion (accessibility and sustainability) with good quality and is created based on a clear purpose, namely, to solve a problem.

Applying this approach, we analyze and interpret the data using a qualitative scoring technique. The data analysis and interpretation focus on eliciting data concerning innovation quality from the respondents and their leadership capacity. The scoring follows that of Corbin and Strauss (2008), namely, procedures for a qualitative and grounded study that suit this type of research. The scoring classifies the data into open, axial, and selective scoring. We used manual scoring to simplify the analysis of the transcripts, using a coding of zero, one, to two for innovation quality and a coding of zero or one for leadership competency. Based on this scoring procedure, we obtain a score of zero to eight for innovation quality and a score of zero to nine for leadership competency.

\section{B. BPF Model}

To analyze transformational leadership potential as a game changer in making breakthroughs by encouraging innovation quality and leadership competency and, hence, encouraging a game-changing frugal innovation, this study offers a new approach, namely, the BPF model. We argue that leadership will push or shift the BPF, reflecting leadership impact and sustainable economic growth. Therefore, the BPF model integrates the individual's or organization's capacity to manage innovation quality, on one hand, and leadership competency, on the other hand. The BPF model has a superior analysis range compared to Bhatti's (2012) model, since it explores not only innovation quality, but also leadership competency, as well as the role of an institutional framework in facilitating breakthroughs.

The study assumes that individuals or organizations have differences and constraints. Regarding the constraints, if a significant breakthrough is not made, 
efforts to encourage innovation quality and/or leadership competency will not extricate a person/organization from those constraints. Consequently, the role of leader as a game changer to make breakthroughs and overcome the constraints will expand the BPF. This condition also reflects leadership potential in terms of exploring new sources of growth while encouraging more sustainable growth.

Intuitively, the role of the institutional framework is key in frugal innovation and transformational leadership, either in tandem or separately. Here, we need not only a leader who is aware of the importance of innovation, but also one who is capable of institutionalizing innovation. Therefore, a good institutional framework will induce leadership potential as a game changer to make breakthroughs and ensure that the innovation process unfolds continuously through a structured or institutionalized innovation pipeline. Breakthroughs that bring about sustainability are the result, while the institutionalization of innovation in the form of platforms or innovation ecosystems is the cause.

In standard analysis, we can assume that institutions are perfect. However, in developing or emerging market countries, including Indonesia, the path to innovation is hampered by weak institutions. Similarly, in this study, we argue that the frugal innovation-transformational leadership nexus requires a conducive regulatory framework; the absence of either will slow down progress in innovation, at the very least. The behavior of such a BPF is illustrated in Figure 1.

Figure 1. BPF

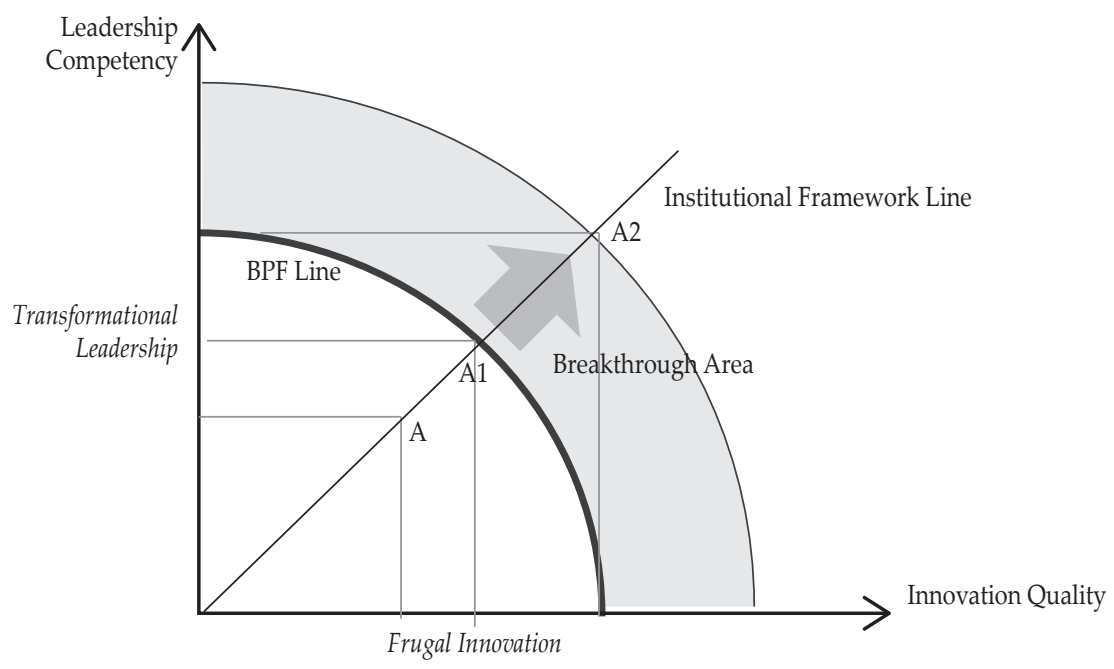

The $x$-axis in Figure 1 depicts the innovation quality variable. As elaborated previously, an innovation born from constraints is known as frugal innovation. Innovation quality is assessed based on two aspects of the impact-sustainability model, namely, reviewing the innovation in terms of impact and sustainability. Higher innovation quality implies a stronger impact and greater sustainability. Meanwhile, the y-axis describes the leadership competency variable. The higher the $y$ value, the more transformational and sustainable the leadership. 
The leader also faces a constraint line. Point A indicates when the leader has not gone beyond the constraint line; in other words, the transformational leadership competencies have not enabled the leader to move beyond the constraint area. Leaders at this level are unable to make breakthroughs until they go beyond the constraint line.

To depict the role of the institutional framework, we draw a 45-degree line from the intersection of the $\mathrm{x}-\mathrm{y}$ axis, suggesting no innovation and leadership for zero institutional quality and, as institutional quality improves, an optimum for innovation and leadership, whereby the curve intersects the 45-degree line, such as at points A1 and A2. Point A1 indicates a leader who has reached the constraint line. This implies that the leader is able to recognize the constraints and tries to overcome them through innovation at a certain level. Leaders at this stage have stronger transformational leadership competencies than those at point A. This is the point at which frugal innovation begins. Point A2 indicates a leader who has passed the constraint line and made a breakthrough. At the next level, the leader will prepare to face the next constraint or standardize his/her behavior to address the constraint he/she previously overcame.

Using this model, we can observe the point at which a leader will produce a frugal innovation. The path created by moving along the $\mathrm{x}$ - and $\mathrm{y}$-axes until the constraint line is met is called the BPF. There are various combinations of transformational leadership competencies and the innovation quality of a leader. As long as the combination touches the constraint line, the leader is perceived as having made a breakthrough. The level of breakthroughs will become optimal as institutional quality, innovation quality, and leadership competency improve to the point where the curve intersects the 45-degree line.

\section{Data}

The data in this study are derived from the answers of 100 respondents and consist of two groups. The first group comprises 50 participants in the Youth Economic Leadership Program (YELP) from 2017 to 2018. YELP is an event held by the Bank Indonesia (BI) Institute consisting of an innovation boot camp designed as a forum to teach and train the young finalists of innovation and leadership contests. The selection was conducted over several stages. Of the 1,200 registrants, the jury selected the 50 with the best ideas and creations in their respective fields. The finalists were asked to describe their views on leadership and the innovations they had created. The data provided information on the participants' roles in terms of their contribution to themselves, their environment, and their neighborhood, a solid indicator for exploring leadership characteristics. The innovation ideas that were proposed will become an indicator for observing the role of frugal innovation from their perspective.

The second group consisted of 50 participants in the Economic Leadership for Regional Government Leaders (REL) from 2017 to 2018. The REL program is a frontier program of the BI Institute that aims to achieve BI's vision of supporting and encouraging regional economic programs in Indonesia. The program is intended for regional leaders, with modules that integrate three critical leadership elements, namely, leaders' skill set, toolset, and mindset. The participants included 
regents, mayors, spokespersons of the City House of Representatives, and heads of BI's Representative Office.

The difference between the two respondent groups involves their leadership manifestation and innovations created. The YELP participants were university students who had never been formal leaders, whereas the REL participants were Indonesian regents or mayors. In other words, the REL participants were formal leaders who had been in office and had gained experience there. In terms of innovation quality, the YELP participants had produced innovations that were primarily still ideas or prototypes, whereas the innovations of the REL participants had already been implemented in their own regions.

\section{ANALYSIS}

This section analyses the behavior of the 100 study participants in terms of measurements of their innovation quality and leadership competency, as explained in the previous section.

First, since the nexus between innovation quality and leadership competency has implications for the proposed conceptual framework and the analysis, we assume no significant bidirectional relation between innovation quality and leadership competency. Although transformational leaders can drive quality innovation, they should generally be complementary. Some leaders can have transformational leadership competencies but lack innovation quality, and vice versa. Only very few leaders have a thorough exposure to both innovation quality and leadership competency. This assumption is supported by nonsignificant correlation coefficients between these two measures in both groups of respondents (i.e., with correlation coefficients around 0.3 for both the YELP and REL participants). This result is also in line with the important role played by a good institutional framework in facilitating breakthroughs and achieving optimal progress in both aspects.

Second, the behavior of the YELP participants can be summarized as follows. In terms of innovation quality, $70 \%$ of their problem identification is based on assumptions rather than objective data, $73 \%$ created an innovation to solve a specific problem, $78 \%$ of the innovations were not on target, $55 \%$ of the innovations were still in the form of ideas that required huge resources for implementation, and $80 \%$ had an impact that is difficult to measure. Meanwhile, in terms of leadership competency, the YELP participants typically lacked sufficient leadership experience. Therefore, the participants' degree of transformational leadership competency is moderate rather than high.

Third, the behavior of the YELP participants can be summarized as follows. In terms of innovation quality, the REL respondents naturally made innovations specific to their corresponding regions and that could not be easily replicated, despite their impact on regional economic growth. Average frugal innovation quality is not yet optimal, therefore, the innovations cannot be replicated. Consequently, the REL participants' degree of frugal innovation quality can still be improved. In terms of leadership competency, the REL respondents are normally endowed with one or more combinations of transformational leadership competencies and sustainable leadership characteristics. The regional leaders had 
a vision that was later integrated into an innovation program in their respective regions. Generally, this vision also departed from problem identification based on objective data, experiences, and assumptions. These leaders were also able to achieve breakthroughs and had the ability to solve problems and make decisions. The average degree of transformational leadership competency of these respondents was already high.

The behaviors notes above led to the following conclusions

(i) Innovation quality and leadership competency differ between the two groups. In this regard, the REL participants had better ability than the YELP participants in terms of both innovation quality and leadership competency. This result is logical, because the REL participants were leaders with experience in office, whereas the YELP participants were only university students, despite their having passed a stringent selection process as finalists in innovation competitions.

(ii) Generally, correspondence bias (positive correlation) between innovation quality and leadership competency is statistically nonsignificant. In this regard, not all the REL participants were able to drive innovation quality because of their leadership competency/experience. On the other hand, the innovations of the YELP participants, who were young and lacked experience in public office, were dominated by ideas and prototypes. Considering their identification process, around $50 \%$ of the YELP participants based their problem identification on general assumptions rather than objective data. Moreover, their innovations are not on target, required more resources for implementation, and had an impact that was difficult to measure. In contrast, this did not apply to the remaining $50 \%$ of the YELP participants, who had already achieved quality innovation, despite lacking sufficient leadership experience.

\section{A. BPF Model Analysis}

The identification data of the YELP and REL participants concerning innovation quality and leadership competency are now applied to the BPF model. The distribution, presented in Figure 2, shows the respective positions of the YELP and REL participants in the model. On average, the YELP participants belonged to point (a), where innovation does not yet have the frugal innovation criteria and transformational leadership competencies are not yet developed. By comparison, the REL participants belonged to point (b), namely, leaders who have made breakthroughs using transformational leadership capabilities, despite a lack of frugal innovation quality. 
Figure 2. BPF curve of the YELP and REL participants

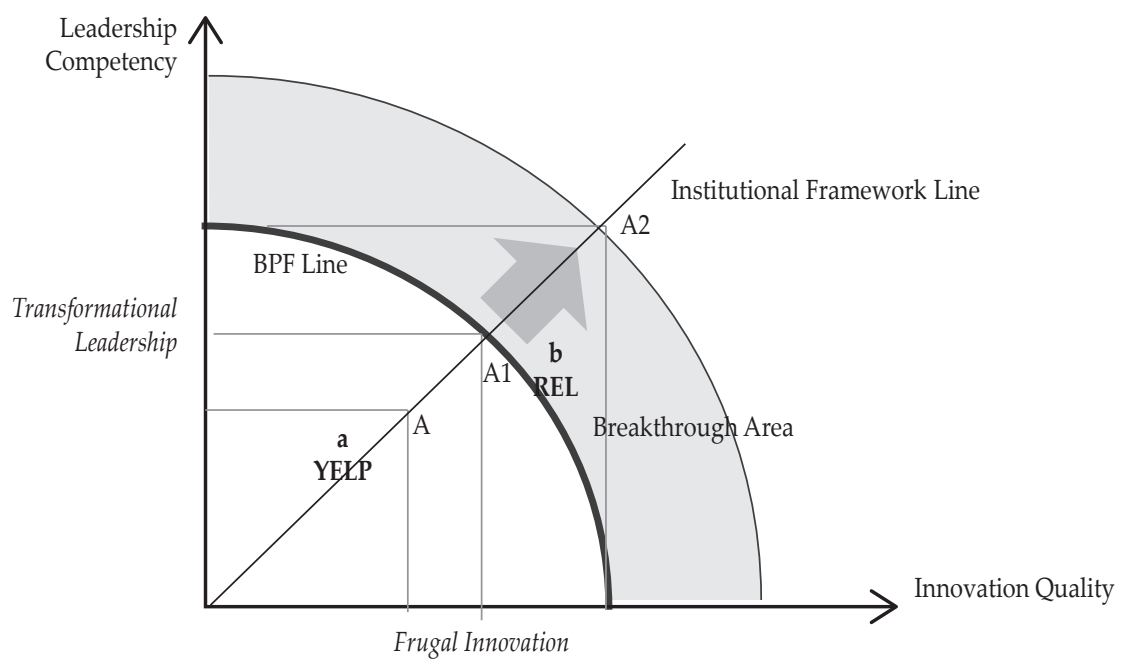

Based on the BPF model, there are several alternative steps that should be taken by a leader as a game changer to accomplish a breakthrough. These include balancing innovation quality with leadership competency to reach or go beyond the BPF line that intersects the 45-degree line of the established institutional framework.

To facilitate breakthroughs in the creation of game-changing frugal innovation, a leader must correctly carry out each innovation design process stage. First, in the creation stage, an innovation must begin with the ability to explore a clear and specific problem. The leader must explore society's needs through empirical data rather than subjective experience or assumptions. Exploration of the empirical data will help the leader identify and describe the problems, identify constraints, and set targets to be accomplished. Thereafter, the problem statement created from those data must be clear and straightforward so it can be connected to a specific objective. An innovation based on a specific problem and a clear objective will be relevant and highly impactful.

The second matter is to encourage value creation. The value creation process relates closely to the previous process, namely, problem identification. To create a value-added innovation, the leader must synchronize the innovation and the identified problem. Furthermore, the value creation process is also correlated with frugal innovation quality. The quality of the innovation that is offered must exceed that of existing innovations, despite lower prices or production costs. Transformational leadership competencies play a crucial role when encouraging value creation through frugal innovation. Problem solving relates to the ability to identify a specific value creation, and social intelligence relates closely to the ability to empathize with the real needs behind the innovation.

The process of creating innovation significance is related to the previous two processes. If, in the previous two processes, the leader manages to correctly and specifically identify a problem, the innovation will tend to be on target. At this stage, 
leadership capacity is needed to solve the problem and make a decision based on the identified problem. With leadership capacity, ultimately, the innovation that the leader is trying to create can be a solution to the current problem, as required. Significance still relates to innovation quality. Frugal innovation must be of good quality, with simple but non-superfluous features, as required to meet the needs of a specific target.

The next matter involves encouraging implementation potential/feasibility. Frugal innovation must prioritize resourcefulness in its implementation plan. A leader must take advantage of surrounding resources in the implementation process, especially when beset by constraints. The innovation must also be affordable and simple to ensure implementation. The leader must be realistic and efficient. Therefore, in this regard, transformational leadership competencies such as breakthroughs, agility, problem solving ability, and decision making ability are desirable. Leaders must create breakthroughs and remain agile amid the problems they are trying to solve.

The final process in the creation of frugal innovation is enlarging the impact. Innovation must originate from a specific purpose to create impact. Clear purpose and vision play a crucial role at this stage. Innovation with a clear and specific target will create a larger and more measurable impact. Impact relates closely to sustainability. An innovation is considered highly impactful if it is sustainable and benefits society socioeconomically while avoiding any detrimental impact on the environment. A transformational leader plays an important role in this regard. Through competencies, such as breakthroughs, social intelligence, problem solving, and decision making, the leader will be able to create innovation that could become a breakthrough and encourage social inclusion and cohesion. The leader can thus enhance his or her potential by improving the nine transformational leadership competencies identified by Juhro and Aulia (2018) and highlighted earlier.

\section{CONCLUSION AND IMPLICATIONS}

Based on the results of our analysis, we draw the following conclusions. First, frugal innovation plays a crucial role in the development of new sources of economic growth in this era of technological development. Technological advances have grown exponentially, on a global scale, making frugal innovation a relevant solution to current problems, especially in emerging markets. Frugal innovation represents a breakthrough that can arise from constraints, offering new breakthroughs and affordable solutions that benefit society (i.e., social inclusion) and the environment (i.e., sustainability). Frugal innovation quality is correlated with the stage of innovation strategy, namely, problem identification (accessibility and purpose), value creation (quality and purpose), suitability (sustainability, quality, and purpose), implementation (affordability, accessibility, and simplicity), and impact (accessibility, sustainability, quality, and purpose). The higher the quality of these innovation stages, the more relevant frugal innovation will be as a new source of growth, thus leading to breakthroughs and sustainable growth.

Second, transformational leadership plays a crucial role in encouraging and orchestrating innovations. In this regard, transformational leadership can serve as a game changer through various breakthroughs to drive game-changing frugal 
innovation, which can become a strategic driver of growth. Transformational leaders can potentially create game-changing, impactful, and sustainable innovation despite constraints.

Third, our analysis demonstrates the important roles of innovation quality and leadership competency as new sources of growth. This study offers a new approach, namely, the BPF model, which integrates an individual's or organization's ability to increase innovation quality (frugal innovation), on the one hand, and leadership competency (transformational leadership), on the other. The analysis reveals that, given a well-developed institutional framework, the transformational leadership role is required to make breakthroughs and encourage game-changing frugal innovation as a strategic driver of growth.

From these conclusions, we draw the following fundamental implications. First, to enhance an economic breakthrough in an era replete with scarcity and constraints, leaders are expected to enhance their leadership competency and innovation quality. Therefore, leaders are required to participate in training on innovation, creativity, problem solving, empathy, and other related matters. Specifically, transformational leadership competencies must be included in compulsory training materials if breakthroughs are desired. Public and private sector leaders are advised to master transformational competencies in this everchanging era.

Finally, based on the BPF model, we recommend the establishment of an integrated institutional framework for promoting innovation. Along with this institutional framework, policymakers should establish innovative leadership development programs to teach transformational leadership competencies, enabling leaders to optimally accomplish breakthroughs and orchestrate innovation. Such a program should address regional heads, such as mayors and regents, to develop innovation capacity and quality and to create projects that can be easily implemented and replicated in other regions, to extend the impact beyond regional borders.

To this end, the manifestation of frugal innovation and transformational leadership in all public and private sector leaders at all levels will enhance synergy, as well as inter-regional and intra-regional collaboration, that will ultimately enhance the regional economy. In the aggregate, regional economic growth will culminate in stronger and more sustainable national economic growth.

\section{REFERENCES}

Axon, L., Friedman, E., \& Jordan, K. (2015). Leading Now: Critical Capabilities for a Complex World. Cambridge: Harvard Business Publishing.

Baker, S. (2015). Sustainable Development. London: Routledge, Taylor \& Francis Ltd. Bappenas. (2011). Masterplan Percepatan dan Perluasan Pengembangan Ekonomi Indonesia 2011-2025. Retrieved from https://www.bappenas.go.id/index.php/ download_file/view/11060/3437/ at November $10^{\text {th }} 2018$.

Barden, M., \& Morgan, A. (2015). A Beautiful Constraint: How to Transform Your Limitations into Advantages, and Why It's Everyone's Business. New York: Wiley. 
Bass, B. M. (1990). From Transactional to Transformational Leadership Learning to Share the Vision. Organizational Dynamics, 18, 19-32.

Basu, R. R., Banerjee, P. M., \& Sweeny, E. G. (2013). Frugal Innovation: Core Competencies to Address Global Sustainability. Journal of Management for Global Sustainability, 1, 63-82.

Bhatti, Y. (2012). What is Frugal, What Is Innovation? Towards a Theory of Frugal Innovation. Retrieved from https://papers.ssrn.com/sol3/papers.cfm?abstract_ $\mathrm{id}=2005910$ at November $10^{\text {th }} 2018$.

Bhatti, Y., Basu, R., Barron, D., \& Ventresca, M. (2018). Frugal Innovation: Models, Means, Methods. Cambridge: Cambridge University Press.

Burns, J.M. (1987). Leadership. New York. Harper \& Row.

Bryman, B., \& Bell, E. (2011). Business Research Methods, 3rd Ed. Oxford: Oxford University Press.

Bound, K., \& Thronton, I. (2012). Our Frugal Future: Lessons from India's Innovation System. London: Nesta Operating Company.

Carlaw, K. I., \& Lipsey, R. G. (2006): GPT-Driven, Endogenous Growth. The Economic Journal, 116, 155-174.

Charan, R. (2009). Leadership in the Era of Economic Uncertainty: Managing in a Downturn. McGraw-Hill.

Chersbrough, H. (2003). RED Through Open Innovation. Retrieved from https:// www.strategy-business.com/article/21626?gko=c2045 at November $10^{\text {th }} 2018$.

Corbin, J., \& Strauss, A. (2008). Basics of Qualitative Research: Techniques and Procedures for Developing Grounded Theory, 3rd Ed. Thousand Oaks, CA: Sage Publications, Inc.

Corrado, C. A., Haskel, J., Jona-Lasinio, C., \& Iommi, M. (2012), Intangible Capital and Growth in Advanced Economies: Measurement Methods and Comparative Results. INTAN-Invest Mimeo.

Creswell, J. W. (2014). Research Design: Qualitative, Quantitative and Mixed Methods Approaches. Thousand Oaks, CA: Sage.

Elkins, T., Keller, R. T. (2003). Leadership in Research and Development Organizations: A Literature Review and Conceptual Framework. Leadership Quarterly, 14, 587-606.

Food and Agriculture Organization of the United Nations (FAO). (2018). Tackling Poverty and Hunger through Digital Innovation. Retrieved from http://www.fao. org/3/ca1040en/CA1040EN.pdf at October 29th 2018.

Fu, X., Pietrobelli, C. and Soete, L. (2010). The Role of Foreign Technology and Indigenous Innovation in the Emerging Economies: Technological Change and Catching-up. World Development, 39, 1204-1212.

Fullan, M. (2004). Leadership E Sustainability: System Thinkers in Action. Thousand Oaks, CA: Corwin Press.

García-Morales, V. J., Lloréns-Montes, F. J., Verdú-Jover, A. (2008). Influence of Personal Mastery on Organizational Performance through Organizational Learning and Innovation in Large Firms and SMEs. Technovation, 27, 547-568.

George, G., McGahan, A. M., \& Prabhu, J. (2012). Innovation for Inclusive Growth: Towards a Theoretical Framework and a Research Agenda. Journal of Management Studies, 49, 1-23. 
Gumusluoglu, L., \& Ilsev, A. (2007). Transformational Leadership, Creativity, and Organizational Innovation. Journal of Business Research, 62, 461-473.

Hargreaves, A., \& Fink, D. (2000). Three Dimensions of Educational Reform. Educational Leadership, 57, 30-34.

Hargreaves, A., \& Fink, D. (2003). The Seven Principles of Sustainable Leadership. Journal of the Department of Supervision and Curriculum Development, N.E.A., 61, 8-13.

Hunt, J. G., Stelluto, G.E. and Hooijberg, R. (2004). Toward New-Wave Organization Creativity: Beyond Romance and Analogy in the Relationship Between Orchestra-Conductor Leadership and Musician Creativity. Leadership Quarterly, 15, 145-62.

International Monetary Fund. (2018). World Economic Outlook: Challenges to Steady Growth. Washington, DC, October.

Jerrim J. (2013). The Reading Gap: The Socio-Economic Gap in Children's Reading Skills: A Cross-National Comparison using PISA 2012. Paris: OECD.

Juhro, S. M., \& Aulia, A. F. (2018), Transformational Leadership through Applied Neuroscience: Transmission Mechanism of the Thinking Process. International Journal of Organizational Leadership, 7, 211-229.

Kaplinsky, R. (2011). Schumacher Meets Schumpeter: Appropriate Technology below the Radar. Research Policy, 40, 193-203.

Karadal, H., \& Saygin, M. (2011). The Effect of Information Technology on Innovation Abilities: A Research on SMEs. International Conference on Eurasian Economies, 2, 396-399.

Khan, R. (2016). How Frugal Innovation Promotes Social Sustainability. Sustainability, 8, 1034.

Kock, A., \& Gemünden, H. G. (2016). Antecedents to Decision-Making Quality and Agility in Innovation Portfolio Management. Journal of Product Innovation Management, 33, 670-686.

Koellinger, P. (2008). The Relationship Between Technology, Innovation, and Firm Performance-Empirical Evidence from e-Business in Europe. Research Policy, Vol. 37, 1317-1328.

Lawrence, K. (2013). Developing Leaders in a VUCA Environment. UNC Executive Development:1-15.

Le Bas, C. (2016). The Importance and Relevance of Frugal Innovation to Developed Markets: Milestones towards the Economics of Frugal Innovation. Journal of Innovation Economics \& Management, 21, 3-8.

Lembaga Ilmu Pengetahuan Indonesia. (2013). Inovasi Frugal: Tantangan dan Peluang Penelitian dan Pengembangan Serta Bisnis di Indonesia. Jakarta: PAPPIPTEK LIPI.

NESTA. (2009). The Innovation Index: Measuring the UK's Investment in Innovation and its Effects. Available at https://www.nesta.org.uk/report/innovationindex-2009/.

Ojha, N.P. \& Ayilavarapu, D. (2016). Leapfrogging the World with Frugal Innovation. Available at https://www.bain.com/insights/leapfrogging-world-with-frugalinnovation-livemint/.

Organisation for Economic Co-operation and Development (OECD). (2004). Innovation and Economic Growth. Available at https://www.oecd.org/cfe/ tourism/34267902.pdf 
OECD. (2012). Innovation and Inclusive Development Conference Discussion Report. Presented at Cape Town, South Africa, November 21 2012.

OECD. (2013). New Sources of Growth: Knowledge-Based Capital-Key Analyses and Policy Conclusions -Synthesis Report. Available at https://www.oecd.org/sti/ inno/knowledge-based-capital-synthesis.pdf.

Prahalad, C. K. (2005). The Fortune at the Bottom of the Pyramid: Eradicating Poverty with Profits. Philadelphia: Wharton Business Publishing.

Raghuramapatruni, R., \& Kosuri, S. (2017). The Straits of Success in a VUCA World. IOSR Journal of Business and Management (IOSR-JBM), 1, 16-22.

Schumpeter, J. A. (1949). Theory of Economic Development. Cambridge, MA: Harvard University Press.

US Department of Commerce. (2012). 2011 Annual Report: Powering Export Growth. Retrieved from https://2016.trade.gov/cs/cs_annualreport12.pdf.

Weyrauch, T., \& Herstatt, C. (2016). What Is Frugal Innovation? Three Defining Criteria. Journal of Frugal Innovation, 2, 1.

Woodridge, J. (2010). Econometric Analysis of Cross Section and Panel Data. Cambridge: MIT Press.

World Economic Forum. (2017). The Global Risks Report 2017, 12 ${ }^{\text {th }}$ Ed. Geneva: World Economic Forum.

World Bank. (2018). Available at http://www.worldbank.org/en/news/pressrelease/2018/06/05/global-economy-to-expand-by-3-1-percent-in-2018-slowergrowth-seen-ahead.

Zeschky, M., Widenmayer, B., \& Gassmann, O. (2011). Frugal Innovation in Emerging Markets. Research-Technology Management, 54, 38-45.

Zhao, Z. Y., \& Lei, X. P. (2013). Empirical Analysis of the Relationship between Technology Innovation and Basic Research. Current Science, 104, 714-720. 
This page is intentionally left blank 